\title{
Adaptability and Trait Stability Analysis in Volvariella volvacea (Paddy Straw Mushroom)
}

\author{
Ved Prakash Sharma, Anil Kumar*, Anupam Barh, \\ Shwet Kamal and Satish Kumar
}

ICAR-Directorate of Mushroom Research, Chambaghat, Solan, Himachal Pradesh- 173213, India

*Corresponding author

\section{A B S T R A C T}

\section{Keywords}

AMMI, Genotypeenvironment interaction, Paddy straw mushroom, Stability analysis

Article Info

Accepted:

12 March 2019

Available Online:

10 April 2019

\begin{abstract}
Under present investigation, AMMI (Additive main effects and multiplicative interaction) model was validated to study and identify the stable genotype in Volvariella volvacea (Paddy straw mushroom) under varied environmental conditions. A slight change in temperature and humidity can cause larger difference in the crop yield. Moreover, the identification of strain selection criteria for better yield is also needed to be identified for genetic improvement. The six strains of Volvariella volvacea (DMRO888, DMRO886, DMRO463, DMRO889, DMRO885 and DMRO484) were cultivated on cotton ginning mill waste substrate for the characterization of their agronomical traits. The correlation studies showed that yield was highly positively correlated with six traits namely total fruit body length (TFBL), Pileus diameter (PD), Gill width (GW), Stipe length (SL), Fruit body weight $(\mathrm{FBW})$ and fruit body number (FBN) while it is negatively correlated with spawn run time (SRT). The DMRO463 was found most stable and average yielder is the all environment. Further the path correlation identified that PD and FBN traits are the best criteria for the selection of high yielding strain in screening experiments.
\end{abstract}

\section{Introduction}

Paddy straw mushroom (Volvariella volvacea) is an edible mushroom of warm and humid areas and it is known for its nutritional value, unique aroma and texture. It grows well between 28 and $34^{\circ} \mathrm{C}$ temperature (Bao et al., 2013; Chang, 1969, 1978; Tao et al., 2014). This mushroom ranks sixth in the global production of cultivated mushrooms and accounts for 5-6\% of world production (Buswell and Chen, 2005).It has significant pharmacological properties, including antitumor polysaccharides, immune suppressive proteins and immunomodulatory lectins (Kishida et al., 1992; She et al., 1998). Compared to many cultivated species of mushrooms, the productivity of $V$. volvacea is relatively low (Chang, 1974). The reasons for the low productivity of the paddy straw mushroom could be many, however, lack of stable yield and efficient selection criteria is of utmost importance. Since yield is affected by many traits therefore it is necessary to find 
out such characters which are linked to the yield directly or indirectly. Environmental factors like growing seasons, temperature, humidity etc. either put positive or negative impacts on genotypes. The interaction effect of genotype (G) and environment (E) complicates the selection of superior genotypes under different sets of environmental conditions. $\mathrm{G}$ x $\mathrm{E}$ interaction made it possible to confirm particular genotypes of $V$. volvacea being superior in particular environments. The hypothesis of our experiment was to find the stable variety of V.volvacea, which can provide a uniform and high yield in all season and to assess the most influential traits affecting the yield positively. So that it can be used for selection in genetic improvement programme.

\section{Materials and Methods}

The present investigation was carried out during the years 2017-2018 at ICARDirectorate of Mushroom Research, Solan, Himachal Pradesh. The six strains (DMRO888, DMRO886, DMRO463, DMRO889, DMRO885 and DMRO484) of Volvariella volvacea were cultivated in three different times i.e. June-July (E1), AugustSeptember (E2) and November-December (E3) for identification of stable cultivar for commercial breeding. The three cropping season was taken as three different environment namely E1, E2 and E3.

Ready to use spawn of test strains was prepared by using chopped paddy straw. Cotton ginning mill waste was utilized as substrate to evaluate the test of $V$. volvacea strains under this study. Substrate was composed for 4 days outdoor and then pasteurized/conditioned for 4 days in the cropping room itself. Beds were prepared with $20 \mathrm{~kg}$ wet substrate on the shelves of iron racks. During spawn run, temperature of $32 \pm 2{ }^{0} \mathrm{C}$ was maintained in the cropping room.
After the spawn run the temperature difference were created during the cropping by inducing fresh air thus temperature were kept $32-34^{0} \mathrm{C}$ for $\mathrm{E} 1,30-32^{\circ} \mathrm{C}$ for $\mathrm{E} 2$ and $28^{0} \mathrm{C}-30^{0} \mathrm{C}$ for E3. Water was sprayed on the beds, if moisture in substrate found below the desired level.

Each trial was conducted in Randomized complete block design (RCBD) with seven replications. Each strain was planted in beds and each bed was taken as replication for the experiment. The identification of yield related traits for genotype environment interaction $(\mathrm{G} \times \mathrm{E})$ was also studied for possible yield related traits (Dia et al., 2017). The totals of eleven observations were taken in related to yield and related traits. The following traits data was taken during the experiment viz. Spawn run time (SRT), Total fruit body length (TFBL), Pileus diameter (PD), Gill width (GW), Stipe top width (STW), stipe base width (SBW), Stipe length (SL), Basal diameter (BD), Fruit body number (FBN), Fruit body weight (FBW) and Yield (Y). The correlation and path correlation was also studied to find out the traits related to yield for selection of cultivation with their direct and indirect effects.

\section{AMMI Statistical analysis}

The AMMI (Additive main effects and multiplicative interaction) model was taken to study and identify the stable genotype. AMMI is ANOVA (analysis of variance) based approach that dissects total variation into genotypes $(\mathrm{G})$, environment $(\mathrm{E})$ and their interaction $(\mathrm{G} \times \mathrm{E})$. The $\mathrm{G} \times \mathrm{E}$ interaction is analyzed with principal components analysis (PCA) (Zobel et al., 1988). Graphic representations obtained using biplots (Gabriel, 1971). In biplots, the angles between the vectors of strains and cropping times show the interaction, and the distances from the origin indicate the degree of interaction that 
the genotypes show throughout the environments or vice versa. The statistical analysis was done using $\mathrm{R}$ statistical software (Dia et al., 2017).

\section{Results and Discussion}

The AMMI ANOVA obtained showed that the all strains showed highly significant difference for all traits based on their genetic material. The sole environment does not affect the SRT and PD traits while SRT is affected by genotype and environment interaction. Out of all traits only four characters SRT, FBN, FBW and Y showed highly significant $\mathrm{G} \times \mathrm{E}$ interaction (Table 1). Previous studies have also reported mushroom crops very susceptible to the variable climatic conditions (AMGA, 2004; Van Peer et al., 2009). In the present studies also test strains were exposed to three different environments and significant effect on some major traits was recorded. The AMMI biplots were generated for all the major traits and PCA1 value for all traits was found more than $80 \%$ of total variation of interaction sum of squares. The AMMI1 and AMMI2 biplot were obtained for all traits. The AMMI1 biplot of SRT showed that genotype DMRO886 showed lesser mean value for the spawn run time in all environments. This variety therefore can be utilized for the source of genes for development of shorter duration varieties in paddy straw mushroom. The AMMI1biplot also showed that E1 and E2 are helpful in decreasing spawn run time that is in summers and late summers while E3 winter increased the spawn run time (Fig. 1). The AMMI2 showed that variety DMRO889 and DMRO886 is best responded for the E2 environment while DMRO463 is showed the better interaction with E3 (Fig. 2). Mahalingam et al., (2017) also utilize the similar methodology to test the six short duration genotype of rice under fifteen locations to check their adaptability (Mahalingam et al., 2006).

The AMMI 2 analysis showed that FBN was found higher in the environment E1(summer month) and reduced in E2 (late summer) and E3 (winter) environment. In contrast to FBN, FBW showed reverse trend as E3 environment helped to produce higher fruit body weight (FBW). This clearly indicates that comparatively lower temperature during fruit body development may cause increase in fruit body weight due slower development hence more accumulation of biomass. The fact for this might be that low temperature stress conditions, decreased the cell division and differentiation and increased the accumulation of dry matter content (Schuppler et al., 1988). The FBN were found maximum for DMRO886 and showed good interaction with the E1 environment while DMRO484 found to have lower FBN and showed interaction with E2 environment. FBW was found maximum of DMRO886 genotype that was positively interacted with E3. The DMRO888 showed the lowest fruit body weight and interaction with E1 environment. The genotypes DMRO463 and DMRO885 showed a stable fruit body weight across the entire environments taken in study. Similarly FBN was also stable in these two genotypes only. The yield was found maximum in environment $\mathrm{E} 1$ which is obvious as it is natural grown season of paddy straw mushroom while E2 and E3 showed comparatively lesser yield than E1 environment. The genotypes DMRO886, DMRO889 and DMRO885 were found suitable for the E1 environment while DMRO484 and DMRO889found suitable to E2 and E3 respectively. The DMRO463 was found most stable and average yielder is the all environment. Our work shows some concurrence with the finding of Dia et al., (2018), who evaluated 22 pickling genotypes in 7 locations across the United States and 
based on the stability statistics, they explored the possibilities to breed stable cucumber genotypes with high yield. Yield itself is complex traits i.e. it is governed by many other traits. These traits are correlated to yield directly or may be through other traits. To identify high yielding cultivars these correlated traits are very useful. The phenotypic selection criteria can be ascertained by these traits and helpful in large genotypic screening. For identification of such traits correlation combined with path correlation is a useful tool. In study the correlation analysis showed that yield was highly positively correlated with six traits namely TFBL, PD, GW, SL, FBN and FBW while it is negatively correlated with SRT (Table 2). The path correlation studies showed that PD have direct effect on yield and also effect yield positively in through indirectly for many other traits (Table 3 ). It is seen that TFBL, SL, FBN, FBW are indirectly effecting yield through PD. Moreover, the FBN is also showing high direct effect this means that PD and FBN can be excellent selection criteria for the germplasm screening. The residual factor in analysis was found 0.058 which is very low. Traits of like size, shape, weight have been utilized previously as basis for better strain selection in $V$. volvacea strains (Ahlawat et al., 2008; Kumar et al., 2017).

AMMI analysis has been used by many researchers to study the adaptability and yield stability in the varieties of different agriculture crops. Based on the AMMI analysis, genotypes have been recommended for their use under various crop breeding programmes. Rono et al., (2016) reported that the genotype and environment interaction influences the selection criteria of sorghum (Sorghum bicolor) genotypes.

Eight sweet sorghum genotypes were evaluated at five different locations in two growing seasons. They determined the interaction between genotype and environment on cane, juice, and ethanol yield and to identify best genotypes for bioethanol production in Kenya. Oliveira et al., (2014) evaluated the adaptability and yield stability of yellow passion fruit varieties using AMMI (additive main effects and multiplicative interaction). Twelve varieties were evaluated in eight environments. High varietal phenotypic stability was observed in three environments and recommended to be used in yellow passion fruit breeding programs. Silveira et al., (2013) studied the adaptability and the phenotypic stability of sugarcane genotypes in the Minas Gerais state, Brazil, based on the additive main effects and multiplicative interaction (AMMI) method (Silveira et al., 2012). They evaluated 15 genotypes in nine environments. They reported the AMMI method very efficient in identification of superior genotypes for each set of environments. Blanche et al., (2007)used similar methodology and conducted multi-environment trials to determine the performance of genotypes in relation to environmental changes and to determine their area of adaptation (Blanche $e t$ al., 2007).

In the present investigations, we have identified E1 (June-July) as the most favourable season for paddy straw mushroom cultivation. Because of the greater phenotypic stability in test the strains under E1; it can be used during the initial stages of screening new strains of $V$. volvacea. Strain DMRO886 has been identified as the potential source of genes for developing short duration variety under strain improvement programme. SRT, FBN, FBW and Y have been identified as the major phenotypic traits being influenced by the GxE interaction. Sole environment $(\mathrm{E})$ has no effect on SRT, however it has been significantly influenced by the genotype $(G)$ and GxE interaction. 
Table.1 AMMI ANOVA of paddy straw mushroom genotypes

\begin{tabular}{|c|c|c|c|c|c|c|c|c|c|c|c|c|}
\hline \multirow{2}{*}{$\begin{array}{l}\text { Source of } \\
\text { variation }\end{array}$} & \multirow[t]{2}{*}{ df } & \multicolumn{11}{|c|}{ Mean square value } \\
\hline & & SRT & TFBL & PD & GW & STW & SBW & SL & BD & FBN & FBW & $\mathbf{Y}$ \\
\hline Env & 2 & 0.38 & $48.16 * * *$ & 2.18 & $0.42 * * *$ & $0.94 * * *$ & $13.98 * * *$ & $6.25^{* *}$ & $32.90 * * *$ & $10306.2 * * *$ & $271.01 * * *$ & $1470.85^{* * *}$ \\
\hline $\operatorname{Rep}(\operatorname{Env})$ & 18 & 0.90 & $1.66^{*}$ & 1.27 & $0.02 *$ & 0.02 & 0.40 & 0.83 & 0.493 & 492.3 & 19.88 & 24.05 \\
\hline Gen & 5 & $18.08 * * *$ & $21.40 * * *$ & $40.37 * * *$ & $0.47 * * *$ & $0.19 * * *$ & $1.06 * *$ & $19.20 * * *$ & $7.043 * * *$ & $4392.6 * * *$ & $186.64 * * *$ & $589.48 * * *$ \\
\hline Gen:Env & 10 & $4.71 * * *$ & 0.004 & 0.008 & 0.009 & 0.006 & 0.09 & 0.002 & 0.038 & $1359.5 * * *$ & $72.42 * * *$ & $109.42 * * *$ \\
\hline Residuals & 90 & 1.25 & 0.807 & 0.835 & 0.01 & 0.02 & 0.25 & 0.789 & 0.428 & 360.6 & 20.47 & 25.27 \\
\hline
\end{tabular}

Table.2 Correlation between the characters taken in study

\begin{tabular}{|c|c|c|c|c|c|c|c|c|c|c|}
\hline & TFBL & PD & GW & STW & SBW & SL & BD & FBN & FBW & $\mathbf{Y}$ \\
\hline SRT & $\begin{array}{l}- \\
0.681 * * *\end{array}$ & $\begin{array}{l}- \\
0.724 * * *\end{array}$ & $\begin{array}{l}- \\
0.680 * * *\end{array}$ & 0.268 & $0.409 * *$ & $-\overline{0.565 * * *}$ & 0.057 & $-\overline{0.660 * * *}$ & $\begin{array}{l}- \\
0.936 * * *\end{array}$ & $-0.827 * *$ \\
\hline TFBL & & $0.872 * * *$ & $0.835 * * *$ & $-0.416 * *$ & -0.168 & $0.914 * * *$ & $-0.417 * *$ & $0.833 * * *$ & $0.714 * * *$ & $0.788 * * *$ \\
\hline PD & & & $0.890 * * *$ & -0.197 & 0.180 & $0.710 * * *$ & -0.082 & $0.886^{* * *}$ & $0.791 * * *$ & $0.930 * * *$ \\
\hline GW & & & & $-\overline{0.604 * * *}$ & 0.057 & $0.825 * * *$ & -0.123 & $0.713 * * *$ & $0.824 * * *$ & $0.832 * * *$ \\
\hline STW & & & & & $0.389 * *$ & $\begin{array}{l}- \\
0.686 * * *\end{array}$ & $0.348 * *$ & -0.092 & $-0.435 * *$ & -0.209 \\
\hline SBW & & & & & & $-0.315 * *$ & $0.535 * * *$ & -0.017 & $-0.302 *$ & -0.024 \\
\hline SL & & & & & & & $\begin{array}{l}- \\
0.629 * * *\end{array}$ & $0.739 * * *$ & $0.695 * * *$ & $0.696 * * *$ \\
\hline BD & & & & & & & & $-0.447 * *$ & -0.177 & -0.210 \\
\hline FBN & & & & & & & & & $0.753 * * *$ & $0.930 * * *$ \\
\hline FBW & & & & & & & & & & $0.918 * * *$ \\
\hline
\end{tabular}


Int.J.Curr.Microbiol.App.Sci (2019) 8(4): 1462-1471

Table.3 Path correlation of the characters taken in study

\begin{tabular}{|c|c|c|c|c|c|c|c|c|c|c|c|}
\hline \multirow{2}{*}{$\begin{array}{l}\text { Path } \\
\text { correlation }\end{array}$} & \multirow[t]{2}{*}{ Direct effect } & \multicolumn{10}{|c|}{ Indirect effect } \\
\hline & & SRT & TFBL & PD & GW & STW & SBW & SL & BD & FBN & FBW \\
\hline SRT & 0.552 & - & 0.009 & -0.952 & 0.068 & -0.156 & -0.212 & 0.712 & -0.002 & -0.531 & -0.288 \\
\hline TFBL & -0.014 & -0.376 & - & 1.147 & -0.083 & 0.241 & 0.087 & -1.152 & 0.017 & 0.670 & 0.219 \\
\hline PD & 1.315 & -0.399 & -0.012 & - & -0.089 & 0.114 & -0.094 & -0.895 & 0.003 & 0.713 & 0.243 \\
\hline GW & -0.099 & -0.375 & -0.012 & 1.171 & - & 0.351 & -0.030 & -1.040 & 0.005 & 0.574 & 0.253 \\
\hline STW & -0.581 & 0.148 & 0.006 & -0.259 & 0.060 & - & -0.202 & 0.865 & -0.014 & -0.074 & -0.134 \\
\hline SBW & -0.519 & 0.225 & 0.002 & 0.237 & -0.006 & -0.226 & - & 0.396 & -0.022 & -0.014 & -0.093 \\
\hline SL & -1.260 & -0.312 & -0.013 & 0.934 & -0.082 & 0.399 & 0.163 & - & 0.025 & 0.595 & 0.214 \\
\hline BD & -0.040 & 0.032 & 0.006 & -0.108 & 0.012 & -0.202 & -0.278 & 0.792 & - & -0.360 & -0.054 \\
\hline FBN & 0.805 & -0.364 & -0.012 & 1.165 & -0.071 & 0.054 & 0.009 & -0.932 & 0.018 & - & 0.231 \\
\hline FBW & 0.308 & -0.516 & -0.010 & 1.041 & -0.082 & 0.252 & 0.157 & -0.875 & 0.007 & 0.606 & - \\
\hline
\end{tabular}

Residual factor $=0.058$ 


\section{Int.J.Curr.Microbiol.App.Sci (2019) 8(4): 1462-1471}

Fig.1 AMMI 1 biplot between mean value of traits and PC1
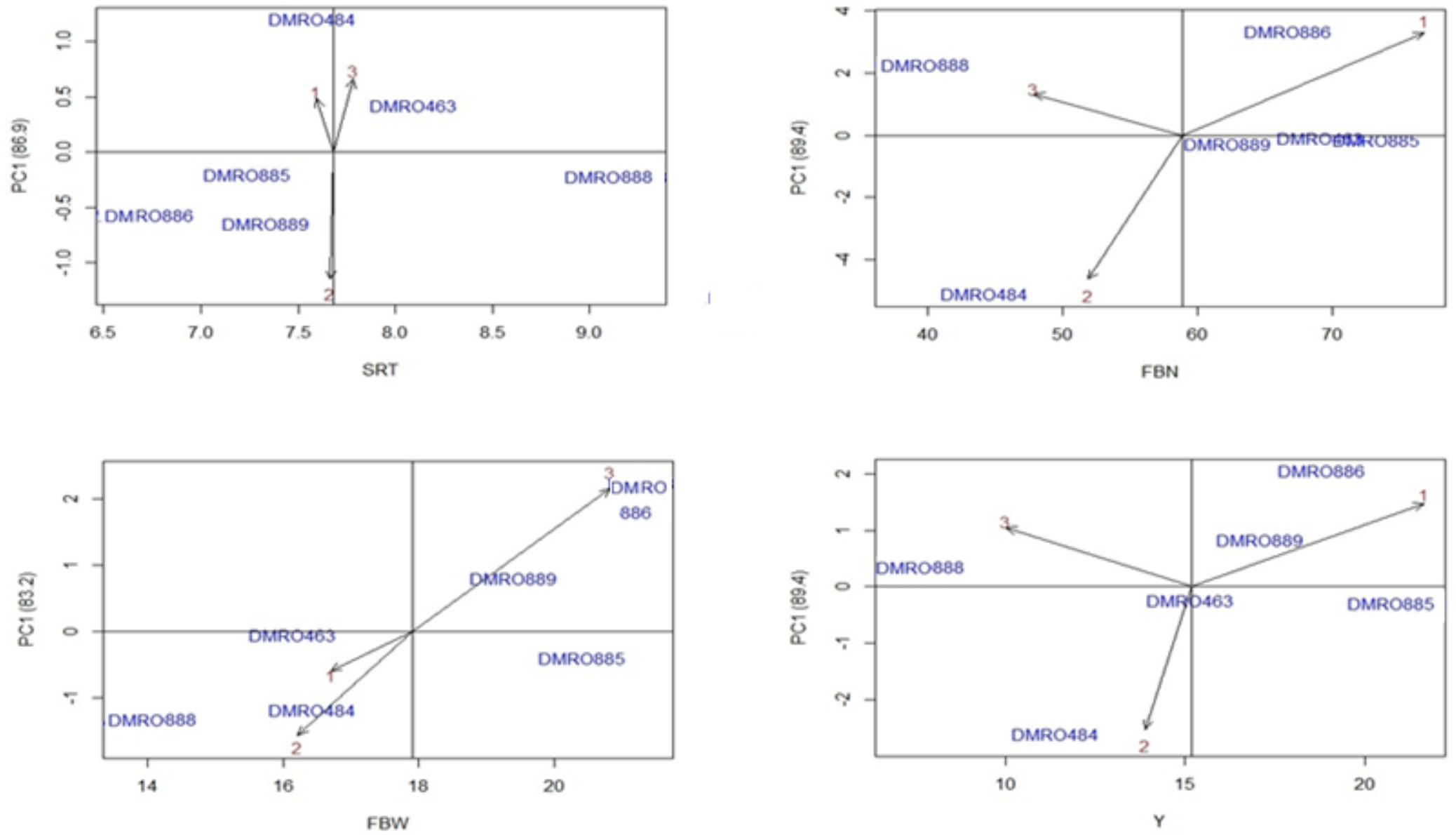


\section{Int.J.Curr.Microbiol.App.Sci (2019) 8(4): 1462-1471}

Fig.2 AMMI 2 biplot between PC1 vs PC2
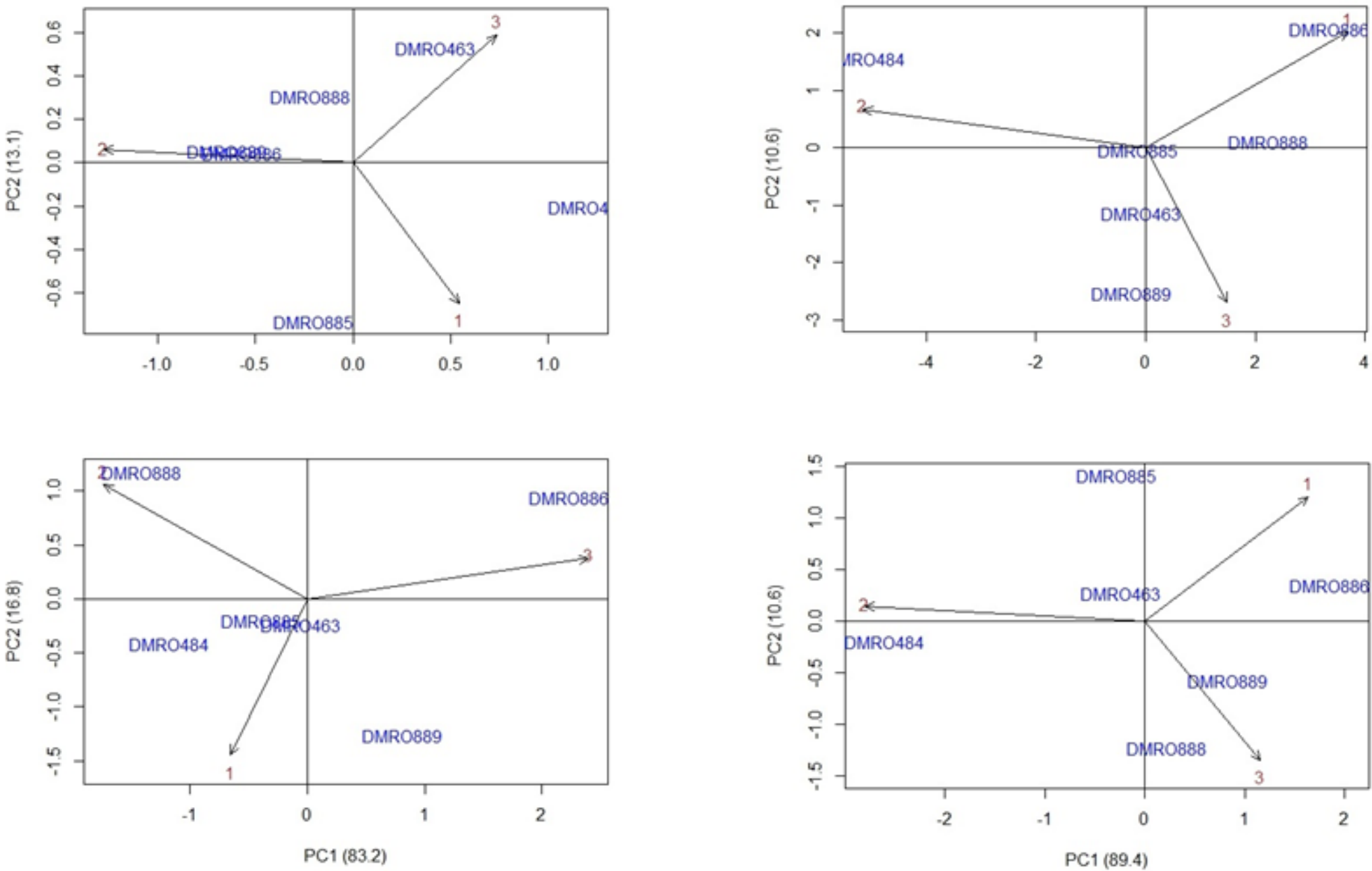
The DMRO463 has been identified as most adaptable average yielder under all environments, whereas, DMRO886, DMRO889 and DMRO885 found suitable for the E1 environment while DMRO484 and DMRO889 for E2 (late summer) and E3 (winter) respectively. Winter season (E3) and DMRO886 genotype have been identified most suitable to get maximum fruit body weight. Our findings will be helpful in round the year cultivation of paddy straw mushroom (V. volvacea).

\section{Acknowledgements}

Authors are thankful to the Director, ICARDirectorate of Mushroom Research, Solan (India) for providing necessary laboratory facilities for conducting the study.

\section{References}

Ahlawat, O. P., Gupta, P., Kamal, S., Dhar, B. L., 2008.Development of molecular and biochemical markers for selecting a potential high yielding strain of paddy straw mushroom (Volvariella volvacea). Journal of Plant Biochemistry and Biotechnology. 17: 57-63. https://doi.org/10.1007/BF03263260

AMGA, 2004. AMGA-Home - Australian Mushroom Growers' Association [WWW Document].

Bao, D., Gong, M., Zheng, H., Chen, M., Zhang, L., Wang, H., Jiang, J., Wu, L., Zhu, Y., Zhu, G., Zhou, Y., Li, C., Wang, S., Zhao, Y., Zhao, G., Tan, Q., 2013. Sequencing and comparative analysis of the straw mushroom (Volvariella volvacea) genome. PLoS ONE 8, e58294. https://doi.org/10.1371/ journal.pone.0058294

Blanche, S. B., Myers, G. O., Kang, M. S., 2007. GGE biplots and traditional stability measures for interpreting genotype by environment interactions.
Journal of Crop Improvement 20: 123135. https://doi.org/10.1300/J411v20n01_07

Chang, S. R., 1969. A cytological study of spore germination of Volvariella volvacea. Botanical Magazine. 82: 102109.

Chang, S. T., 1978. Volvariella volvacea, In: The Biology and Cultivation of Edible Fungi. Academic Press, New York, pp. 573-605.

Chang, S.T., 1974. Production of straw mushroom (Volvariella volvacea) from cotton waste. Mushroom Journal. 21: 348-353.

Dia, M., Wehner, T. C., Arellano, C., 2017.RGxE: An $R$ program for genotype $\mathrm{x}$ environment interaction analysis. American Journal of Plant Sciences. 08: 1672-1698. https://doi. org/10.4236/ajps.2017.87116

Gabriel, K. R., 1971. The biplot graphic display of matrices with application to principal component analysis.Biometrika.58: $\quad 453$. https://doi.org/10.2307/2334381

Kishida, E., Kinoshita, C., Sane, Y., Misaki, A., 1992.structures and antitumor activities of polysaccharides isolated from mycelium of Volvariella volvacea. Bioscience, Biotechnology, and Biochemistry. 56: 1308-1309. https://doi.org/10.1271/bbb.56.1308

Kumar, A., Ahlawat, O.P., Sharma, V.P., 2017. Strain improvement in paddy straw mushroom and their evaluation, In: Biorational approaches in plant disease management and annual meeting of INSOPP. p. 128.

Mahalingam, L., Mahendran, S., Chandra Babu, R., Atlin, G., 2006. AMMI analysis for stability of grain yield in rice (Oryza sativa L.). International Journal of Botany. 2: 104-106. https://doi.org/10.3923/ijb.2006.104.10 6 
Schuppler, U., He, P. H., Peter, C., Munns, R., 1988.Effect of water stress on cell division and cdc2-like cell cycle kinase activity in wheat leaves. Plant Physiology. 87: 50-57. https://doi.org/10.1104/pp.87.1.50

She, Q. B., Ng, T. B., Liu, W. K., 1998. A novel lectin with potent immunomodulatory activity isolated from both fruiting bodies and cultured mycelia of the edible mushroom Volvariella volvacea. Biochemical and Biophysical Research Communications. 247: 106-111. https://doi.org/10.1006/ BBRC.1998.8744

Silveira, L. C. I. da, Kist, V., Paula, T. O. M. de, Barbosa, H.P., Alexandre, L., Daros, E., 2012.AMMI analysis to evaluate the adaptability and phenotypic stability of sugarcane genotypes. Sci. Agric. v 70, 27-32.

Tao, Y., van Peer, A. F., Chen, B., Chen, Z.,
Zhu, J., Deng, Y., Jiang, Y., Li, S., Wu, T., Xie, B., 2014. Gene Expression Profiling Reveals Large Regulatory Switches between Succeeding Stipe Stages in Volvariella volvacea. PLoS ONE 9, e97789. https://doi.org/10.1371/ journal.pone.0097789

Van Peer, A. F., Müller, W. H., Boekhout, T., Lugones, L. G., Wösten, H. A. B., 2009. Cytoplasmic continuity revisited: closure of septa of the filamentous fungus Schizophyllum commune in Response to Environmental Conditions. PLoS ONE 4, e5977. https://doi.org/10.1371/journal.pone.000 5977

Zobel, R. W., Wright, M. J., Gauch, H. G., 1988. Statistical analysis of a yield trial. Agronomy Journal.80: 388 . https://doi.org/10.2134/agronj1988.000 $21962008000030002 x$

\section{How to cite this article:}

Ved Prakash Sharma, Anil Kumar, Anupam Barh, Shwet Kamal and Satish Kumar, 2019. Adaptability and Trait Stability Analysis in Volvariella volvacea (Paddy Straw Mushroom). Int.J.Curr.Microbiol.App.Sci. 8(04): 1462-1471. doi: https://doi.org/10.20546/ijcmas.2019.804.171 